\title{
Is the Walking Campaign Effective for Depressive Symptoms?
}

\author{
Setsuko Taneichi, Fumiharu Togo, Tsukasa Sasaki \\ Laboratory of Health Education, Graduate School of Education, Tokyo, Japan \\ Email: staneichi21@gmail.com, tougou@p.u-tokyo.ac.jp, psytokyo@yahoo.co.jp
}

Received 5 August 2014; revised 2 September 2014; accepted 6 October 2014

Copyright (C) 2014 by authors and Scientific Research Publishing Inc.

This work is licensed under the Creative Commons Attribution International License (CC BY). http://creativecommons.org/licenses/by/4.0/

(c) (i) Open Access

\begin{abstract}
Aim: The aim of this study is to examine the effect of walking 10,000 steps per day on depressive symptoms for the company employees and their spouses in Japan. Method: Subjects were recruited from the participants of a walking campaign carried out by a Japanese company where the goal was to achieve 600,000 steps in 60 days. Among 221 subjects who participated in the campaign, 176 subjects $(79.6 \%)$ agreed to participate in the present study. Sociodemographics and other information including depressive symptoms were assessed using a questionnaire. Result: Out of the 171 participants, 125 achieved the goal (73.1\%). In the achiever's group, the GHQ-12 score was significantly reduced at the end of the campaign compared with the non-achiever's group. Exercise habit and the less overtime work ( $<45$ hours past 1 month) at the baseline were significantly associated with the achievement of the goal. Conclusion: The achievement of 600,000 steps in 60 days is correlated with the improvement of depressive symptoms and the achievement of this goal might be related with the exercise habit and less overtime work before the campaign.
\end{abstract}

\section{Keywords}

Depressive Symptoms, 10,000 Steps, Physical Activity, Walking, Walking Campaign

\section{Introduction}

Depression is one of the most common diseases in developed countries and is predicted to become the world's second leading cause of disability by 2020 [1]. The pharmacotherapy is included in the popular management of depressive symptoms. However, physical activity is also effective to manage depressive symptoms. Several studies showed lower depressive symptoms among physically active people compared to non-active people [2] [3].

According to a review by Teychenne (2008) [4], physical activity of higher intensity was more strongly associated with effective treatment of depressive symptoms than those of lower intensities, but even a low dose of 
physical activity may bring about a positive result for treatment of depressive symptoms [4].

Although more intense physical activity may have a positive effect on the treatment of depressive symptoms, physical activity of vigorous intensity may be a challenge to continue for people without an exercise habit [5]. The portion of the people who can continue physical activity of vigorous intensity may be limited [6]. For those people, walking may be one of the most feasible and common physical activities. Walking is a physical activity of mild to moderate intensity and requires no financial cost and minimal risk of adverse effects [7]. According to a review by Robertson, walking has a statistically significant positive effect on treatment of depressive symptoms [1].

A number of Japanese companies are carrying out walking campaigns for the purpose of health promotion for their employees. The goal set for this campaign is 10,000 steps per day for 60 or 90 days at most of the companies connected with the same health insurance union in Japan.

The aim of the campaign has been focused on its effect on physical health. The effect of walking on mental health, including the treatment of depressive symptoms, is also covered by a review of Roberston et al. [2]. However their report doesn't describe the numbers of the steps of walking for the treatment of depressive symptoms.

In addition, few studies have investigated the effect of the walking campaign on depressive symptoms and several issues remain to be studied. The first issue is whether or not 10,000 steps per day, which is employed in most of the companies, is appropriate for the improvement of depressive symptoms. 10,000 steps is recommended by several guidelines [8] [9], because a number of studies showed the effect of the 10,000 steps to improve physical health [10] [11], while no study focused on the effect of 10,000 steps on depressive symptoms. The second issue is whether the 10,000 steps per day for several months is sustainable for the employees. Related with this issue, what factors are associated with the achievement of 10,000 steps per day may also be a question to be studied. Thus, the aims of this study are summarized as follows. 1) Whether or not the 10,000 steps per day walking campaign is effective for treatment of depressive symptoms. 2) What factors of the individuals are associated with the achievement of the 10,000 steps per day over several months?

\section{Materials and Method}

\subsection{Method and Patient Selection}

The walking campaign was carried out from April 2012 to May 2012 by a Japanese energy company with 2200 Japanese employees. The company advertised the campaign to the all employees and their spouses. 221 subjects participated in the walking campaign. Among the 221, 176 subjects $(79.6 \%)$ agreed to participate in the presented research. The participants who did not answer the questionnaire at the end of the walking campaign were excluded from the analyses. Finally, 171 participants (100 males and 71 females, mean age $45.4 \pm 10.4$ ) who answered the questionnaires both at the baseline and at the end of the walking campaign were studied. All male participants were the company employees and the female participants consisted of 38 employees and 33 spouses of the male employees. These are not overlapping groups.

The pedometers (Yamasa mk-365, Japan Tokyo) were given to the participants before the start of the walking campaign (baseline). The participants were asked to complete the questionnaire with the following information: sociodemographic and other information including age, sex, job content (indoor or housework, outdoor), hours of overtime work (within the past 1 month; $<45$ hours, $\geq 45$ hours) [12], sleep duration (within the past 1 month; 6 hours, $\geq 6$ hours) [13], exercise habit as recreation (Yes, No). The goal of the campaign was 600,000 steps in 60 days (10,000 steps per day on average) during the period of the campaign. Depressive symptoms were also assessed using the Japanese version GHQ-12 (general health questionnaire-12) [14].

\subsection{Statistical Analysis}

A student's t-test was used to examine the difference of age and the GHQ-12 score between achiever's and non-achiever's groups. The changes of GHQ-12 score overtime between achiever's and non-achiever's group was assessed using analysis of covariance (repeated measures ANCOVA), with overtime work and exercise habit as covariates. All statistical analyses were carried out using SPSS 17.0 (IBM, New York, US).

\section{Result}

Table 1 shows the demographic characteristics between achiever's and non-achiever's group. 125 among the 
171 participants achieved the goal ( $\geq 600,000$ steps in 60 days; 10,000 steps per day for 60 days on average) (73.1\%). At the baseline, the GHQ-12 score was not significantly different between the achiever's group and non-achiever's group. However, at the end of the campaign, the GHQ-12 score of the non-achiever's group was significantly higher than the achiever's group. Exercise habit and the less overtime work ( $<45$ hours per month) at the baseline were significantly associated with the achievement.

Table 2 shows the changes of GHQ-12 score of achiever's and non-achiever's groups. Post hoc tests showed that the achiever's group at the end of the campaign exhibited reduced GHQ-12 score (1.42 \pm 1.78$)$ in comparison to the baseline (2.16 \pm 2.41$)$. Post hoc tests also showed that the achiever's group at the end of the campaign exhibited lower GHQ-12 score (1.42 \pm 1.78$)$ in comparison to non-achiever's group ( $2.72 \pm 3.03)$. By using the analysis of repeated measures ANOVA, the difference of GHQ-12 score between achiever's and non-achiever's group was significant (main effect). However, adjusted for overtime work and exercise habit, there were no significant differences for time and group.

Table 1. Demographics and the other characteristics of the subjects at the baseline.

\begin{tabular}{|c|c|c|c|c|c|c|}
\hline & & Achiever & (\%) & Non-achiever & (\%) & p-value \\
\hline Age (year) & & $45.60 \pm 10.59$ & & $45.11 \pm 9.65$ & & NS \\
\hline \multirow[t]{2}{*}{ Sex } & Male & 75 & $(73.5)$ & 27 & (26.5) & \multirow{2}{*}{ NS } \\
\hline & Female & 55 & $(74.3)$ & 19 & $(25.7)$ & \\
\hline \multirow[t]{2}{*}{ Job content } & Indoor or housework & 50 & $(69.4)$ & 22 & $(30.6)$ & \multirow{2}{*}{ NS } \\
\hline & Outdoor & 77 & $(77.8)$ & 22 & $(22.2)$ & \\
\hline Overtime work & $<45$ hours & 122 & $(77.2)$ & 36 & $(22.8)$ & \multirow{2}{*}{$*$} \\
\hline (past 1 month) & $\geq 45$ hours & 9 & $(47.3)$ & 10 & $(52.6)$ & \\
\hline Sleep duration & $<6$ hours & 67 & $(74.4)$ & 23 & $(25.6)$ & \multirow{2}{*}{ NS } \\
\hline (past 1 month) & $\geq 6$ hours & 64 & $(73.6)$ & 23 & $(26.4)$ & \\
\hline \multirow[t]{2}{*}{ Exercise habit } & No & 47 & $(64.4)$ & 26 & (35.6) & \multirow[t]{2}{*}{ * } \\
\hline & Yes & 85 & $(81.0)$ & 20 & $(19.0)$ & \\
\hline \multirow[t]{2}{*}{ GHQ-12 score } & At the baseline & $2.16 \pm 2.41$ & & $2.89 \pm 2.53$ & & NS \\
\hline & At the end of the campaign & $1.43 \pm 1.78$ & & $2.78 \pm 3.03$ & & * \\
\hline
\end{tabular}

Age and GHQ-12 score was analysed by student's t-test. Sex, job content, overtime work, sleep duartion, exercise habit were analysed by $\chi^{2}$ test. Age and GHQ-12 score: mean \pm SD. NS: not significant. ${ }^{*} \mathrm{p}<0.05$.

Table 2. The changes of GHQ-12 score over time achiever's and non-achiever's groups.

\begin{tabular}{|c|c|c|c|c|c|c|c|c|c|c|}
\hline & & & & & & & \multicolumn{2}{|c|}{$\begin{array}{l}\text { Adjusted for } \\
\text { overtime work }\end{array}$} & \multicolumn{2}{|c|}{$\begin{array}{l}\text { Adjusted for } \\
\text { exercise habit }\end{array}$} \\
\hline All & \multicolumn{2}{|c|}{ Achiever's group } & \multicolumn{2}{|c|}{ Non-achiever's group } & \multicolumn{2}{|c|}{ Group $\times$ Time } & \multicolumn{2}{|c|}{ Group $\times$ Time } & \multicolumn{2}{|c|}{ Group $\times$ Time } \\
\hline \multirow[t]{2}{*}{$(\mathrm{n}=171)$} & \multicolumn{2}{|c|}{$(n=125)$} & \multicolumn{2}{|c|}{$(n=46)$} & & & & & & \\
\hline & Mean & $\mathrm{SD}$ & Mean & SD & $\mathrm{F}$ & $\mathrm{p}$ & $\mathrm{F}$ & $\mathrm{p}$ & $\mathrm{F}$ & $\mathrm{p}$ \\
\hline \multicolumn{11}{|l|}{ GHQ-12 mean score } \\
\hline At the baseline & 2.16 & 2.41 & 2.89 & 2.53 & \multirow[b]{2}{*}{8.97} & \multirow[b]{2}{*}{$* *$} & \multirow[b]{2}{*}{1.24} & \multirow[b]{2}{*}{0.27} & \multirow[b]{2}{*}{0.545} & \multirow[b]{2}{*}{0.462} \\
\hline $\begin{array}{l}\text { At the end of the } \\
\text { campaign }\end{array}$ & $1.42^{\dagger}$ & 1.78 & 2.72 & 3.03 & & & & & & \\
\hline
\end{tabular}

Repeated measures ANOVA was used to evaluated the changes in GHQ-12 scores. Repeated measures ANCOVA was used to evaluated the changes in GHQ-12 scores over time with overtime work and exercise habit as covariates. ${ }^{* *} \mathrm{p}<0.005 .{ }^{\dagger}$ Post hoc tests showed that the achiever's group at the end of the campaign exhibited reduced GHQ-12 score $(1.42 \pm 1.78)$ in comparison to the baseline $(2.16 \pm 2.41)$. Post hoc tests also showed that the achiever's group at the end of the campaign exhibited lower GHQ-12 score (1.42 \pm 1.78$)$ in comparison to non-achiever’s group ( $2.72 \pm 3.03)$. 


\section{Discussion}

At the baseline, the GHQ-12 score was not different between the achiever's group and non-achiever's group. At the end of the campaign, the GHQ-12 score was significantly reduced in the achiever's group. On the other hand, the GHQ-12 score did not change in the non-achiever's group. This suggests that the achievement of the 600,000 steps for 60 days may assist with treatment of depressive symptoms. Less overtime work $(<45$ hours per month) and exercise habits maintained before the start of the campaign were significantly associated with the achievement. The repeated measure ANOVA for GHQ-12 score revealed a significant main effect for time and group. This main effect means that GHQ-12 score significantly decreased from at the baseline to the end of the campaign in the achiever's group, but not in the non-achiever's group. Adjusted by overtime work or exercise habit, there were no significant differences for time and group. This result suggest that the subjects who work overtime within 45 hours and have exercise habit before campaign are the most effective to improve the depressive symptoms by participating in the campaign.

In the present study, $26.9 \%$ did not achieve the goal. Considering this rate of the achievement and that only $10 \%$ of the company employees participated in the campaign, whether the 10,000 steps is sustainable for company employees and their spouses may be also an important issue for the treatment of depressive symptoms. One of the factors associated with the non-achievement was overtime work. The association might be due to the lack of time for walking or exercise in subjects who have more overtime work. This should be noted because the workers who work overtime may have an increased risk of depressive symptoms [15] [16]. A considerable portion of the employees might not be able to participate in the campaigns due to the overtime work. In addition, this may be a major limitation of the walking campaigns in Japanese companies.

The present study has several limitations. First, the causal relation between the physical activity and depressive symptoms is not clear due to the study design. It is possible that improved mental health helped to facilitate walking. Second, the association between physical activity and improvement of depressive symptoms could be confounded by several unknown variables, but they were not controlled for in the present study. Third, the timing of the physical activity (during the working-time, commuting-time, housework-time, and leisure-time) is unknown. Several studies showed a stronger association between leisure-time physical activity and improvement of depressive symptoms than other timing physical activity [17]-[20]. Future studies may need the analyses of the optional timing of physical activity for decreasing depressive symptoms. Fourth, statistical power may be limited due to the number of the participants, especially in females. While the male participants consisted of employees only, the females consisted of both the employees and their spouses. Studies in larger sample size, especially in females are needed.

\section{Conclusion}

The achievement of 600,000 steps in 60 days may be associated with the improvement of depressive symptoms. The achievement of the goal might be related with the exercise habit and overtime work (below 45 hours before the start of the walking campaign). In the setting of the goal (the number of the walking steps per day), exercise habit and work condition (overtime work) might be considered.

\section{Acknowledgements}

This study was supported by a grant from National Federation of Workers and Consumers Insurance Cooperatives.

\section{Declaration of Interest}

No conflict of interest declared.

\section{References}

[1] Robertson, R., Robertson, A., Jepson, R. and Maxwell, M. (2012) Walking for Depression or Depressive Symptoms: A Systematic Review and Meta-Analysis. Mental Health and Physical Activity, 6, 66-75. http://dx.doi.org/10.1016/j.mhpa.2012.03.002

[2] Johnson, K.E. and Taliaferro, L.A. (2011) Relationships between Physical Activity and Depressive Symptoms among Middle and Older Adolescents: A Review of the Research Literature. Journal for Specialists in Pediatric Nursing, 16, 
235-251. http://dx.doi.org/10.1111/j.1744-6155.2011.00301.x

[3] Brown, H.E., Pearson, N., Braithwaite, R.E., Brown, W.J. and Biddle, S.J. (2013) Physical Activity Interventions and Depression in Children and Adolescents: A Systematic Review and Meta-Analysis. Sports Medicine, 43, 195-206. http://dx.doi.org/10.1007/s40279-012-0015-8

[4] Teychenne, M., Ball, K. and Salmon, J. (2008) Physical Activity and Likelihood of Depression in Adults: A Review. Preventive Medicine, 46, 397-411. http://dx.doi.org/10.1016/j.ypmed.2008.01.009

[5] Sallis, J.F., Greenlee, L. and McKenzie, T.L. (2001). Changes and Tracking of Physical Activity across Seven Years in Mexican-American and European-American Mothers. Women Health, 34, 1-14. http://dx.doi.org/10.1300/J013v34n04_01

[6] Sallis, J.F., Hovell, M.F. and Richard Hofstetter, C. (1992) Predictors of Adoption and Maintenance of Vigorous Physical Activity in Men and Women. Preventive Medicine, 3, 237-251. http://dx.doi.org/10.1016/0091-7435(92)90022-A

[7] Craig, C.L., Tudor-Locke, C. and Bauman, A. (2007) Twelve-Month Effects of Canada on the Move: A Population-Wide Campaign to Promote Pedometer Use and Walking. Health Education Research, 22, 406-413. http://dx.doi.org/10.1093/her/cyl093

[8] Tudor-Locke, C., Burkett, L., Reis, J.P., Ainsworth, B.E., Macera, C.A. and Wilson, D.K. (2005) How Many Days of Pedometer Monitoring Predict Weekly Physical Activity in Adults? Preventive Medicine, 40, 293-298. http://dx.doi.org/10.1016/j.ypmed.2004.06.003

[9] Tudor-Locke, C., Craig, C.L., Aoyagi, Y., et al. (2011) How Many Steps/Day Are Enough? For Older Adults and Special Populations. International Journal of Behavioral Nutrition and Physical Activity, 28, 80. http://dx.doi.org/10.1186/1479-5868-8-80

[10] Tudor-Locke, C., Craig, C.L., Brown, W.J., et al. (2011) How Many Steps/Day Are Enough? For Adults. International Journal of Behavioral Nutrition and Physical Activity, 28, 79. http://dx.doi.org/10.1186/1479-5868-8-79

[11] Iwane, M., Arita, M., Tomimoto, S., Satani, O., Matsumoto, M., Miyashita, K. and Nishio, I. (2000) Walking 10,000 Steps/Day or More Reduces Blood Pressure and Sympathetic Nerve Activity in Mild Essential Hypertension. Hypertension Research, 23, 573-580. http://dx.doi.org/10.1291/hypres.23.573

[12] Uchida, M., Kaneko, M. and Kawa, S. (2014) Effects of Personality on Overtime Work: A Cross-Sectional Pilot Study among Japanese White-Collar Workers. BMC Research Notes, 7, 180.

[13] van Mill, J.G., Vogelzangs, N., van Someren, E.J., Hoogendijk, W.J. and Penninx, B.W. (2014) Sleep Duration, but Not Insomnia, Predicts the 2-Year Course of Depressive and Anxiety Disorders. Journal of Clinical Psychiatry, 75, 119-126. http://dx.doi.org/10.4088/JCP.12m08047

[14] Armstrong, K. and Edwards, H. (2003) The Effects of Exercise and Social Support on Mothers Reporting Depressive Symptoms: A Pilot Randomized Controlled Trial. International Journal of Mental Health Nursing, 12, 130-138. http://dx.doi.org/10.1046/j.1440-0979.2003.00229.x

[15] Proctor, S.P., White, R.F., Robins, T.G., Echeverria, D. and Rocskay, A.Z. (1996) Effect of Overtime Work on Cognitive Function in Automotive Workers. Scandinavian Journal of Work, Environment \& Health, 22, 124-132. http://dx.doi.org/10.5271/sjweh.120

[16] Chalupka, S. (2012) Overtime Work as a Predictor of a Major Depressive Episode. Workplace Health Saf, 60, 192-20120328-26.

[17] Wise, L.A., Adams-Campbell, L.L., Palmer, J.R. and Rosenberg, L. (2006) Leisure Time Physical Activity in Relation to Depressive Symptoms in the Black Women's Health Study. Annals of Behavioral Medicine, 32, 68-76. http://dx.doi.org/10.1207/s15324796abm3201_8

[18] Chen, L.J., Stevinson, C., Ku, P.W., Chang, Y.K. and Chu, D.C. (2012) Relationships of Leisure-Time and Non-LeisureTime Physical Activity with Depressive Symptoms: A Population-Based Study of Taiwanese Older Adults. International Journal of Behavioral Nutrition and Physical Activity, 9, 28.

[19] Torres, E.R., Sampselle, C.M., Ronis, D.L., Neighbors, H.W. and Gretebeck, K.A. (2013) Leisure-Time Physical Activity in Relation to Depressive Symptoms in African-Americans: Results from the National Survey of American Life. Preventive Medicine, 56, 410-412. http://dx.doi.org/10.1016/j.ypmed.2013.02.013

[20] Yang, X., Telama, R., Hirvensalo, M., Hintsanen, M., Hintsa, T., Pulkki-Råback, L., et al. (2012) Moderating Effects of Leisure-Time Physical Activity on the Association between Job Strain and Depressive Symptoms: The Cardiovascular Risk in Young Finns Study. Journal of Occupational \& Environmental Medicine, 54, 303-309. http://dx.doi.org/10.1097/JOM.0b013e318240df39 
Scientific Research Publishing (SCIRP) is one of the largest Open Access journal publishers. It is currently publishing more than 200 open access, online, peer-reviewed journals covering a wide range of academic disciplines. SCIRP serves the worldwide academic communities and contributes to the progress and application of science with its publication.

Other selected journals from SCIRP are listed as below. Submit your manuscript to us via either submit@scirp.org or Online Submission Portal.
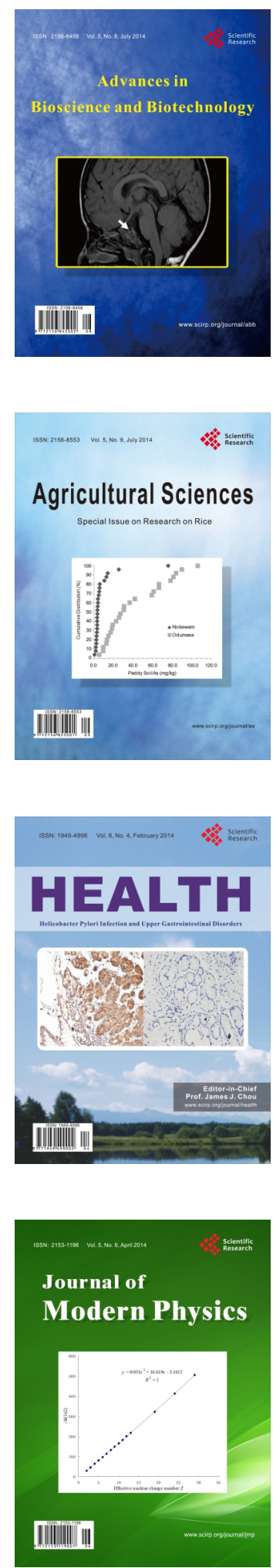
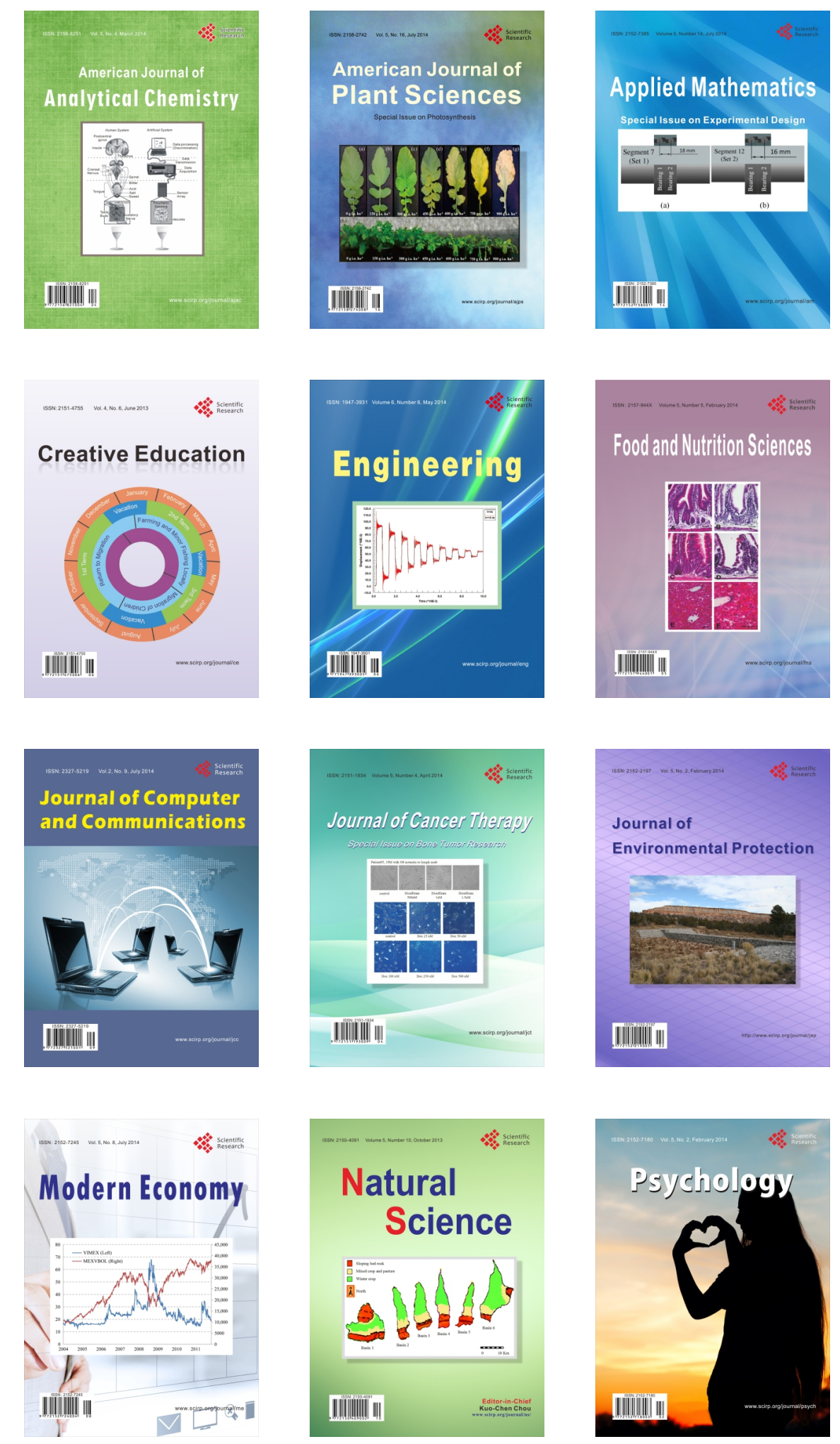